University of Rhode Island

DigitalCommons@URI

Cancer Prevention Research Center Faculty

Publications

Cancer Prevention Research Center

2011

\title{
Adherence to dual-method contraceptive use
}

Jeffrey F. Peipert

Qiuhong Zhao

Laura Meints

Benjamin J. Peipert

Colleen A. Redding

University of Rhode Island, credding@uri.edu

See next page for additional authors

Follow this and additional works at: https://digitalcommons.uri.edu/cprc_facpubs

This is a pre-publication author manuscript of the final, published article.

Creative Commons License

c) (i) $९$

This work is licensed under a Creative Commons Attribution-Noncommercial-No Derivative Works 4.0 License.

\section{Citation/Publisher Attribution}

Peipert, J. F., Zhao, Q., Meints, L., Peipert, B. J., Redding, C. A., \& Allsworth, J. E. (2011). Adherence to dualmethod contraceptive use. Contraception, 84(3), 252-258. doi: 10.1016/j.contraception.2011.01.023

Available at: https://doi.org/10.1016/j.contraception.2011.01.023

This Article is brought to you for free and open access by the Cancer Prevention Research Center at DigitalCommons@URI. It has been accepted for inclusion in Cancer Prevention Research Center Faculty Publications by an authorized administrator of DigitalCommons@URI. For more information, please contact digitalcommons-group@uri.edu. 


\section{Authors}

Jeffrey F. Peipert, Qiuhong Zhao, Laura Meints, Benjamin J. Peipert, Colleen A. Redding, and Jenifer E. Allsworth

This article is available at DigitalCommons@URI: https://digitalcommons.uri.edu/cprc_facpubs/38 


\title{
Adherence to dual method contraceptive use
}

\author{
Jeffrey F. Peipert ${ }^{1,{ }^{*}}$, Qiuhong Zhao, Laura Meints, Benjamin J. Peipert ${ }^{2}$, Colleen A. \\ Redding $^{3}$, and Jenifer E. Allsworth ${ }^{1}$
}

${ }^{1}$ Division of Clinical Research, Department of Obstetrics and Gynecology, Washington University in St. Louis School of Medicine, St. Louis, Missouri, $63110{ }^{2}$ Brown University, Providence, Rhode Island ${ }^{3}$ Cancer Prevention Research Center; University of Rhode Island, Kingston, Rhode Island

\section{Abstract}

Background-Patient characteristics associated with adherence to dual method contraceptive use are not known.

Study Design-Project PROTECT was a 24-month long randomized trial designed to promote the use of dual methods of contraception using an individualized computer-based intervention or enhanced standard care counseling intervention. We analyzed 463 women with follow-up data and examined sustained dual method use (reported at $2+$ interviews).

Results-While 32\% initiated dual method contraceptive use, only $9 \%$ reported sustained use. Education increased $\left(\mathrm{RR}_{\mathrm{adj}}=4.42 ; 95 \% \mathrm{CI} 1.19-16.42\right)$, substance abuse decreased $\left(\mathrm{RR}_{\mathrm{adj}}=0.49\right.$; 95\% CI 0.24-0.97), no contraceptive use at baseline decreased $\left(\mathrm{RR}_{\mathrm{adj}}=0.32 ; 95 \% \mathrm{CI} 0.11-0.92\right)$, and contraceptive stage of change increased $\left(\mathrm{RR}_{\mathrm{adj}}=5.04 ; 95 \% \mathrm{CI} 1.09-23.4\right)$ adherence to dual method use.

Conclusion-To effectively prevent sexually transmitted diseases (STIs) and unplanned pregnancies, dual method use must be consistent and sustained. Future interventions to promote dual method use should focus on high-risk groups and additional dual method combinations (e.g., barrier plus intrauterine devices or implants).

\section{Keywords}

Dual methods; adherence; compliance; STD prevention contraception

\section{Introduction}

Both unintended pregnancies and sexually transmitted infections (STIs) are major public health concerns in the U.S. and the international community. In the U.S., the majority of births to young women are unintended [1.2], and these unintended births are associated with increased risk of poor health outcomes for both mother and child [3]. Moreover, STIs are on the rise in the U.S. [4]. Untreated STIs can lead to pelvic inflammatory disease, ectopic

(C) 2013 Elsevier Inc. All rights reserved.

*Corresponding author: Jeffrey F. Peipert, MD, PhD, Vice Chair of Clinical Research, Division of Clinical Research, Department of Obstetrics and Gynecology, Washington University in St. Louis School of Medicine, Campus Box 8219, 4533 Clayton Avenue, St. Louis, Missouri 63110, peipertj@ wudosis.wustl.edu, Telephone: 314-747-4016, Fax: 314-747-4019.

Publisher's Disclaimer: This is a PDF file of an unedited manuscript that has been accepted for publication. As a service to our customers we are providing this early version of the manuscript. The manuscript will undergo copyediting, typesetting, and review of the resulting proof before it is published in its final citable form. Please note that during the production process errors may be discovered which could affect the content, and all legal disclaimers that apply to the journal pertain. 
pregnancy, chronic pelvic pain, and tubal factor infertility and may facilitate HIV transmission.

No one contraceptive method is effective at preventing both unintended pregnancies and STIs. Dual method contraceptive use, or the use of both a barrier method (e.g., male condoms) and a method more effective at pregnancy prevention (intrauterine devices, implants, hormonal methods, and sterilization), has been proposed as one strategy to effectively prevent both unintended pregnancies and STIs [5-7]. Recent analyses have shown that if half of all women using effective contraceptive methods (e.g., oral contraceptives, contraceptive rings, patches, etc.) alone also used condoms, approximately $40 \%$ of unplanned pregnancies and abortions would be prevented [8]. This percentage rises to $80 \%$ if all women currently using effective methods alone started to also use condoms [8]. Thus, adding condoms to commonly used hormonal contraceptives will increase contraceptive effectiveness. In addition, dual-method contraceptive use, when used consistently, can prevent pregnancy and STIs $[9,10]$. Winner et al. found that consistent condom use reduced incident human papillomavirus (HPV) infection by $70 \%$ [11]. Currently, between $11 \%$ and $38 \%$ of U.S. women 35 years of age and younger use dualmethod contraception $[12,13]$.

Few intervention studies have demonstrated acceptance and adherence to dual method use. We developed and tested an intervention to promote dual contraceptive use in a randomizedclinical trial. In this trial, while the tailored, individualized intervention promoted initiation of dual method use, many women were unable to sustain use over time. However, participants who adhered to dual method use had lower rates unintended pregnancy at 24 months $\left(\mathrm{HRR}_{\mathrm{adj}}=0.36,95 \% \mathrm{CI} 0.15,0.91\right)[14]$. The purpose of this secondary analysis was to determine whether certain baseline patient demographic and reproductive characteristics could predict adherence to dual method contraceptive use over 24 months.

\section{Materials and methods}

A complete description of the methods of Project PROTECT and the primary outcomes of the trial have been previously published $[10,14]$. We briefly review the methods of this trial below, and describe our analytic technique to assess predictors of adherence to dual method use. The project was reviewed and IRB-approved prior to recruitment.

Eligibility for Project PROTECT included the following: 1) female gender between the ages of 13 and 35 years; 2 ) sexually active with a male partner in the past six months; 3 ) high risk for unintended pregnancy or STI; and 4) English-speaking. All sexually active women under 25 years of age were considered high risk, and women 25 years and older were included if they had the following risk factors: 1) history of unintended pregnancy; 2) history of a STI; 3) inconsistent use of contraception; 4) multiple sexual partners; or 5) substance abuse. Women were excluded if they were pregnant, had a hysterectomy or sterilization, or were unable to consent.

Participants were randomly assigned to a tailored, individualized intervention based on the transtheoretical model of behavior change $[10,15,16]$ or to an enhanced standard care (comparison) group. The intervention group received computer delivered information sessions tailored for the use of dual-method contraception, while the comparison group received non-tailored standard care information and advice [10]. All participants were given a packet of educational information with information on dual method use and a sample condom.

We collected the following participant information at baseline: demographics, reproductive history, sexual history, STI history, current and past contraceptive use, substance abuse, 
domestic violence, and levels of stress, and five stages change for contraceptive use. In the three early stages (Precontemplation, Contemplation and Preparation), the participant is not using a contraceptive method consistently; the stages vary on their degree of intention to initiate use (Precontemplation - no intention to start within six months; Contemplation thinking about starting within six months; Preparation - planning to start in next 30 days). In the two advanced stages of change (Action and Maintenance) the participant is using a contraceptive method consistently (Action: < 6 months; Maintenance $>6$ months). Such stage definitions are consistent with prior transtheoretical model research [10, 15-17]. We attempted to contact participants by telephone at 6 and 18 months post-baseline to assess recent sexual history, contraceptive use, and attitudes regarding dual method use, and to determine if participants experienced any clinical outcomes including incident STI and/or unplanned pregnancy. At 12 and 24 months after baseline, participants returned for followup examinations, including STI and pregnancy tests, and follow-up surveys.

The primary outcome of this trial was self-reported initiation of dual methods of contraception. Any of the following were considered acceptable dual method use: (1) use of hormonal contraception plus a barrier method; (2) male condoms plus female condoms; (3) condoms plus spermicide; (4) intrauterine device or sterilization plus a barrier method. Dual method use was classified from the number of follow-up interviews (at 6,12, 18, or 24 months) where dual method use was reported as: never initiated dual method use, initiated use (single follow-up) or sustained use ( 2 or more follow-ups). Median days of dual method use were estimated from the start of dual method use to either the end of dual method use or censoring.

Categorical variables were evaluated using the chi-square or Fisher's exact test as appropriate. Continuous variables were evaluated using a Student's t-test. Median days of dual method use were compared using a median test. Since our outcome variable had three categories, multinomial logistic regression models were conducted. Multinomial logistic regression models can handle outcomes that are polytomous, i.e. more than 2 categories, in one run, with one category specified as the base outcome. Here in our analysis, with no initiation of dual method use as the base outcome, crude and adjusted relative risks were estimated for initiated and sustained dual method use. Crude means that there was single covariate in the regression model, while the adjusted means that some other covariates were adjusted for in the regression models. An adjusted model was used to control for possible confounding between intervention, other covariates, and adherence.

There was significant missing data in the outcome - only $46 \%$ of participants had information on dual method use for all four follow-up time points. Our primary data analysis assumed that missing observations were equal to zero (or no dual method use; intent-to-treat analysis). Because this assumption could have biased the result, we completed three additional analyses to determine the robustness of the current findings: 1) complete case only (N=211); 2) last value carried forward (LVCF); and 3) next observation carried back (NOCB). For both the LVCF and NOCB approaches, missing observations were replaced by either the last or next complete observation. Each of these approaches provided estimates of relative risks similar to those of the primary data analysis, indicating that our findings were robust and not significantly impacted by bias. All analyses were performed using Stata 11 (StataCorp, College Station. Texas).

\section{Results}

Between October 1999 and October 2003, 542 women were enrolled in Project PROTECT and randomized to the individualized intervention or enhanced standard care groups. The demographic and reproductive data of our population were presented in our original report 
$[9,12]$. Briefly, the median age of the population was 22 years, $26 \%$ were black, $17 \%$ were Hispanic, $25 \%$ had less than a high school education, and $48 \%$ were smokers. Four hundred sixty-three (85\%) of the 542 original participants had at least one follow-up interview, forming the sample for this secondary analysis. Table 1 contains the demographic and reproductive characteristics of these participants.

Approximately one-third of participants $(150 / 463=32.4 \%)$ initiated dual method use during 24 months of observation. In our original analysis, the intervention group was associated with increased initiation of dual method use $\left(\mathrm{HRR}_{\mathrm{adj}}=1.7095 \%\right.$ CI 1.09, 2.66), after controlling for imbalances in the randomization groups [14]. Other predictors of initiation of dual-method use included educational level, substance use, and hormonal contraceptive use or condom use at baseline. There were no differences between the 2 groups in terms of biological outcomes (unintended pregnancies or incident STIs (35\% intervention v. 34\% control; $\mathrm{HRR}_{\text {adj }} 1.08$ (95\% CI 0.81, 1.44)). However, women who reported dual-method use on two or more follow-up questionnaires had a significantly reduced risk of unintended pregnancy compared to women who reported dual use less than two times $\left(\operatorname{HRR}_{\text {adj }} 0.36\right.$, $95 \%$ CI, $0.15,0.91)[14]$.

Of the total sample of 463 women with available follow-up information, only 9.3\% (43/463) reported dual method use on 2 or more follow-up visits. This is only $28.7 \%$ (43/150) of women who initiated dual method use. However, due to missing data, the $9.3 \%$ may be an underestimate of the rate of dual method use at 2 or more follow-up visits. Even with imputing missing data, the intervention failed to promote adherence to dual methods; more than three quarters of women $(63 / 82=77 \%)$ who initiated dual method use did not adhere to consistent and sustained use.

We assessed the number of interviews in which dual method use was reported. In our bivariate analysis, level of education, no contraception use at baseline, substance abuse, and advanced contraceptive stage of change (action or maintenance) were significantly associated with two or more follow-up visits where dual method use was reported. These findings persisted in our multivariable analysis after adjusting for confounding factors such as education, substance use, contraceptive use at baseline, treatment group and stages of change (Table 2). Education (2-year degree or more: $\mathrm{RR}=4.42 ; 95 \%$ CI 1.19, 16.42), substance abuse $\left(\mathrm{RR}_{\mathrm{adj}}=0.49 ; 95 \%\right.$ confidence interval $\left.(\mathrm{CI}) 0.24,0.97\right)$, no contraception at baseline $\left(\mathrm{RR}_{\mathrm{adj}}=0.32 ; 95 \% \mathrm{CI} 0.11,0.92\right)$, and advanced contraceptive stage of change (RR $=5.04 ; 95 \%$ CI 1.09, 23.4) remained significant in the multivariable model. Age, race, smoking status, history of unintended pregnancy, male condom use at baseline, lifetime number of sexual partners, number of sexual partners in the past month, sex after drinking alcohol, and forced sex in the past year were not significant predictors of dual contraceptive method initiation.

In our multinomial regression analysis, four characteristics were noted to be associated with adherence to dual method use: 1) level of education increased adherence; 2) no contraceptive use at baseline decreased adherence; 3) substance abuse decreased adherence; and 4) advanced stage of change (i.e., action or maintenance) increased adherence. These associations remained in several models where we imputed missing data, regardless of method chosen for imputation. Analysis of the total dataset $(\mathrm{N}=463)$ and an analysis of the participants with complete information at all four time-points $(\mathrm{N}=211)$ found similar relationships. 


\section{Discussion}

We found that the tailored, individualized intervention based on the transtheoretical model of behavior change resulted in an increase in initiation of dual-method contraception use, but no change in STI incidence or number of unplanned pregnancies compared to enhanced standard care counseling. This study is unique in analyzing the factors related to nonadherence to dual methods. We noted that certain demographic, reproductive, and behavioral characteristics were associated with failure to adhere to consistent dual-method use: lower educational level, no previous contraceptive use, substance use, and less advanced stage of change.

Other investigators have demonstrated that condoms must be used consistently and correctly to prevent STIs [18-20]. Self-reports of condom use are unreliable. Thus, it is no surprise that we did not see a reduction of the biological outcomes of incident STI and unintended pregnancy given the level of adherence. Less than $10 \%$ of the cohort reported consistent dual method use. Participants who reported adherence to dual-method use had the lowest rates of STIs and unintended pregnancies at 24 months [14].

Little is known, however, about factors contributing to initiation of dual-method contraception and to continued use. Whether educational level improves adherence to recommended medical regimens is unclear. Several studies have failed to show an association between education and adherence [21,22], while others have shown an association [23]. Lower educational level has been correlated with poor adherence to use of contraceptives, and by extension poor adherence to dual-methods of contraception [23]. Our study shows a significant relationship between lower educational level and non-adherence to dual method use. Without consistent use, dual contraceptive method use will not substantially affect the incidence of STIs or unplanned pregnancy.

Interestingly, although substance use was negatively associated with initiation of dualmethod contraception and adherence to dual method use, sex after drinking alcohol and smoking status were not associated with initiation or adherence. Additional research is needed to elucidate the relationship between the context of substance use and dual-method contraception initiation and continuation.

Lack of prior contraceptive use was similarly correlated with poor adherence to dual-method contraception. Alternately, more advanced baseline contraceptive stage of change, action or maintenance, significantly predicted initiation and adherence to dual method use. Those who were already using contraception at baseline were more likely to maintain dual method use compared to those who were not. Patients who previously used either oral contraceptives or condoms were more likely to use dual contraceptive methods consistently. Past experience helped maintain the repetition and routine necessary for effective use of contraception. In addition, the hurdle to initiate and maintain the use of two methods is lower for women who are already successfully using one of these methods.

In the transtheoretical model, action and maintenance stages reflect that the participant was already using one contraceptive method consistently $[10,15,16]$. It is not surprising that these patients were able to initiate and adhere to dual method contraceptive use. Dual method use can also be viewed as multiple behavior change. In contrast to other studies that found comparable rates of change in smokers changing one versus more than one behavior at a time [24], we found that those who had already adopted one behavior (use of one contraceptive method) were more likely to adopt and maintain dual method use. Establishing a women's stage of change for contraceptive use may assist clinicians to identify who is more likely to adhere to the recommendation of consistent dual method use. 
Often, failure to initiate and adhere to consistent dual method use was not due to the patient's inability to adhere to dual-methods, but their partner's unwillingness to use condoms. In a previous report, we found that male's unwillingness to use condoms and young age combined with low condom self-efficacy score were associated with unprotected intercourse [25]. In these cases, education for male partners, either individually or in coupleoriented education, may help increase adherence to male condoms. Furthermore, other female-controlled barrier methods (e.g., diaphragm, sponge, or cap) could be offered to women who cannot successfully negotiate condom use with their male partner. However, studies demonstrating the effectiveness of female-controlled barrier methods for STI prevention are lacking [26,27].

The strengths of this study include prospective assessment of dual method use over a 24month period, sample size, and the diverse cohort of women at high-risk for unintended pregnancy and STIs. As a secondary analysis we were limited to available data and, therefore lacked information on relationship status and characteristics. Wilson and Koo [28] examined contraceptive use among low-income women and found a higher probability of dual method use among non-cohabitating women who reported emotionally supportive relationships with their partners and among those who sought to avoid pregnancy. Duration of relationship was not related to dual method use.

Limited patient exposure to the individualized intervention was one constraint of this study. There were no "booster" interventions or reminders beyond the third month. Increasing the number of intervention sessions and providing more information about contraceptive methods and dual methods over time may lead to even greater initiation and continuation of dual method contraceptive use. Similarly, additional interventions targeting or tailoring to those with lower levels of education and those with limited or no experience with contraceptive use could enhance the efficacy of this intervention approach. With the increased use of long-acting contraceptive methods such as intrauterine devices and implants, future studies should assess interventions that couple these highly effective methods at pregnancy prevention with barrier methods for STI prevention. A recent study has shown that women using long-acting methods use condoms less frequently than women using oral contraceptives [8]. Thus, more emphasis on dual methods will be necessary.

In conclusion, many experts have suggested that dual method contraceptive use is the optimal strategy for STI and unplanned pregnancy prevention [6,7]. However, few controlled interventions have demonstrated initiation and adherence to dual method use. A significant limitation to many intervention studies is the reliance on self-report of condom use. Validation of condom use using markers such as the Y-chromosome (Yc), may be helpful to validate reported condom use [29]. Future interventions that promote dual method contraception will have to demonstrate initiation and adherence to see a reduction in the biological outcomes of STIs and unplanned pregnancies. If effective, these interventions have the potential to have a lasting impact on both individuals and society.

\section{Acknowledgments}

Project PROTECT was funded by award R01 HD036663. This research was also supported in part by a Midcareer Investigator Award in Women's Health Research (K24 HD01298), by a Clinical and Translational Science Award (UL1RR024992), and by Grant Number KL2RR024994 from the National Center for Research Resources (NCRR), a component of the National Institutes of Health (NIH) and NIH Roadmap for Medical Research. Its contents are solely the responsibility of the authors and do not necessarily represent the official view of NCRR or NIH. Information on NCRR is available at http://www.ncrr.nih.gov/. Information on Re-engineering the Clinical Research Enterprise can be obtained from http://nihroadmap.nih.gov/clinicalresearch/overview-translational.asp. 


\section{References}

[1]. National Campaign to Prevent Teen and Unplanned Pregnancy - Unplanned Pregnancy and Birth Data. 2010. Available at: http://www.thenationalcampaign.org/national-data/unplannedpregnancy-birth-rates.aspx. Retrieved November 6

[2]. Hellerstedt WL, Pirie PL, Lando HA, et al. Differences in preconceptional and prenatal behaviors in women with intended and unintended pregnancies. Am J Public Health. 1998; 88:663-6. [PubMed: 9551015]

[3]. MMWR Surveillance Summary. Preconception and interconception health status of women who recently gave birth to a live-born infant - Pregnancy Risk Assessment Monitoring System (PRAMS), United States, 26 Reporting Areas, 2004. Vol. 56. Centers for Disease Control and Prevention; Dec 14. 2007 p. 1-35.Available at: http://www.cdc.gov/mmwR/preview/mmwrhtml/ ss5610a1.htm. Retrieved November 5, 2010

[4]. Centers for Disease Control and Prevention. Sexually Transmitted Diseases Surveillance, 2007. Available at: http://www.cdc.gov/std/stats07/toc.htm. Retrieved November 6, 2010

[5]. Crosby RA, DiClemente RJ, Windgood GM, et al. Correlates of using dual methods for sexually transmitted diseases and pregnancy prevention among high-risk African-American female teens. J Adolesc Health. 2001; 28:410-4. [PubMed: 11336871]

[6]. Cates W Jr, Steiner MJ. Dual protection against unintended pregnancy and sexually transmitted infections. What is the best contraceptive approach? Sex Transm Dis. 2002; 29:168-74. [PubMed: 11875378]

[7]. Family Health International. Dual Protection: Best approach to recommend may vary. Network. 2003; 22(4) Available at: http://www.fhi.org/en/RH/Pubs/Network/v22_4/nt2244.htm. Retrieved November 6, 2010.

[8]. Pazol K, Kramer MR, Hogue CJ. Condoms for dual protection: patterns of use with highly effective contraceptive methods. Public Health Rep. 2010; 125:208-17. [PubMed: 20297747]

[9]. Bearinger LH, Resnick MD. Dual method use in adolescents: a review and framework for research on use of STD and pregnancy protection. J Adolesc Health. 2003; 32:340-9. [PubMed: 12729983]

[10]. Peipert J, Redding CA, Blume J, et al. Design of a stage-matched intervention trial to increase dual method contraceptive use (Project PROTECT). Contemporary Clinical Trials. 2007; 28:626-37. [PubMed: 17374567]

[11]. Winer RL, Hughes JP, Feng Q, et al. Condom use and the risk of genital human papillomavirus infection in young women. N Engl J Med. 2006; 354:2645-54. [PubMed: 16790697]

[12]. Santelli JS, Warren CW, Lowry R, et al. The use of condoms with other contraceptive methods among young men and women. Fam Plann Perspect. 1997; 29:261-7. [PubMed: 9429871]

[13]. Santelli JS, Davis M, Celentano DD, Crump AD, Burwell LG. Combined use of condoms with other contraceptive methods among inner-city Baltimore women. Fam Plann Perspect. 1995; 27:74-8. [PubMed: 7796900]

[14]. Peipert JF, Redding CA, Blume JD, et al. Tailored intervention to increase dual-contraceptive method use: a randomized trial to reduce unintended pregnancies and sexually transmitted infections. Am J Obstet Gynecol. 2008; 198:630.e1-630.e8. [PubMed: 18395692]

[15]. Redding CA, Prochaska JO, Pallonen UE, et al. Transtheoretical individualized multimedia expert systems targeting adolescents' health behaviors. Cog Behav Practice. 1999; 6:144-53.

[16]. Prochaska, JO.; Redding, CA.; Evers, K. The transtheoretical model and stages of change. In: Glanz, K.; Rimer, BK.; Viswanath, KV., editors. Health Behavior and Health Education: Theory, Research and Practice. 4th Edition. Jossey-Bass, Inc; San Francisco, CA: 2008. p. 170-222.Chapter 5 in

[17]. Galavotti C, Cabral RJ, Lansky A, et al. Validation of measures of condom and other contraceptive use among women at high risk for HIV infection and unintended pregnancy. Health Psychol. 1995; 14:570-8. [PubMed: 8565932]

[18]. Nielson CM, Harris RB, Nyitray AG, Dunne EF, Stone KM, Giuliano AR. Consistent condom use is associated with lower prevalence of human papillomavirus infection in men. J Infect Dis. 2010; 201(202):445-51. [PubMed: 20569156] 
[19]. Frezieres RG, Walsh TL, Nelson AL, Clark VA, Coulson AH. Evaluation of the efficacy of a polyurethane condom: Results from a randomized, controlled clinical trial. Fam Plann Perspect. 1999; 31:81-87. [PubMed: 10224546]

[20]. Crosby RA, DiClemente RJ, Wingood GM, Lang D, Harrington KF. Value of consistent condom use: a study of sexually transmitted disease prevention among African American adolescent females. Am J Pub Health. 2003; 93:901-902. [PubMed: 12773349]

[21]. Kelly A, Worth H, Man N, Nosi S, et al. Barriers and facilitators for adherence to antiretroviral therapy in Papua, New Guinea. Curr HIV Res. Oct 13.2010 epub ahead of print.

[22]. Goldfarb-Rumyantzev AS, Wright S, Ragasa R, Ostler D, et al. Factors associated with nonadherence to medication in kidney transplant recipients. Nephron Clin Pract. 2010; 117:c33c39. [PubMed: 20689323]

[23]. Lopez LM, Hiller JE, Grimes DA. Postpartum education for contraception: a systematic review. Obstet Gynecol Surv. 2010; 65:325-31. [PubMed: 20591202]

[24]. Prochaska JJ, Velicer WF, Prochaska JO, Delucchi K, Hall SM. Comparing intervention outcomes in smokers treated for single versus multiple behavioral risks. Health Psychol. 2006; 25:380-8. [PubMed: 16719610]

[25]. Peipert JF, Lapane KL, Allsworth JE, et al. Women at risk for sexually transmitted diseases: correlates of intercourse without barrier contraception. Am J Obstet Gyn. 2007; 197:474.e1-e8.

[26]. Minnis AM, Padian NS. Effectiveness of female controlled barrier methods in preventing sexually transmitted infections and HIV: current evidence and future research directions. Sex Transm Infect. 2005; 81:193-200. [PubMed: 15923284]

[27]. Elias C, Coggins C. Acceptability research on female-controlled barrier methods to prevent heterosexual transmission of HIV: Where have we been? Where are we going? J Womens Health Gend Based Med. 2001; 10:163-73. [PubMed: 11268299]

[28]. Wilson EK, Koo HP. Associations between low-income women's relationship characteristics and their contraceptive use. Persp Sex Reprod Health. 2008; 40:171-9.

[29]. Rose E, Diclemente RJ, Wingood GM, et al. The validity of teens' and young adults' selfreported condom use. Arch Pediatr Adolesc Med. 2009; 163:61-4. [PubMed: 19124705] 


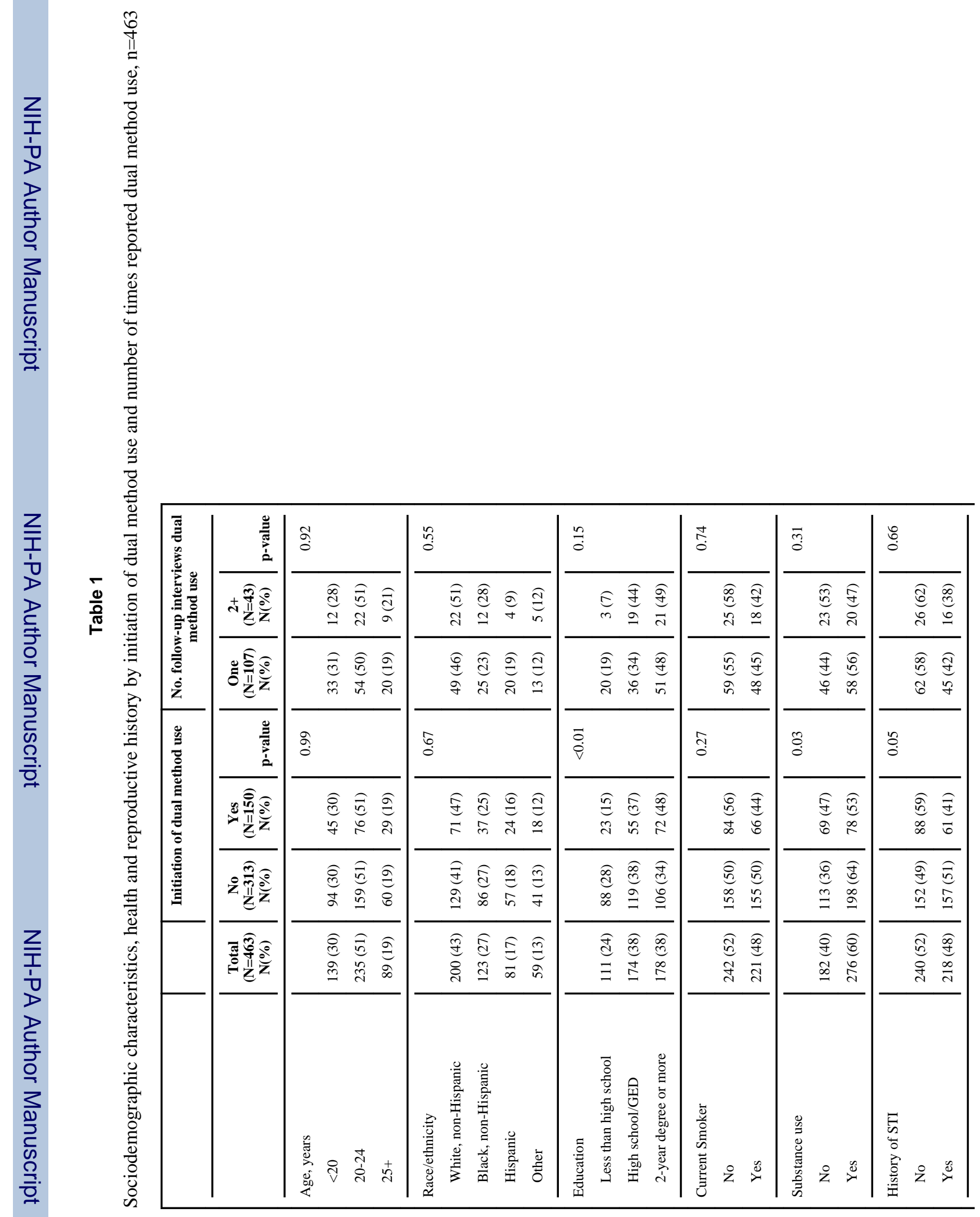




\begin{tabular}{|c|c|c|c|c|c|c|c|c|}
\hline 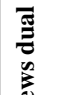 & 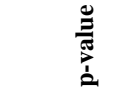 & తి & $\stackrel{\overbrace{}}{0}$ & fo & d़ & $\stackrel{\mathbb{2}}{0}$ & $\stackrel{े}{0}$ & $\bar{n}$ \\
\hline 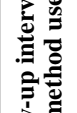 & $+\frac{\widehat{a}}{\pi} \bar{z}$ & 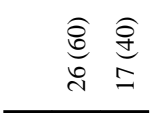 & 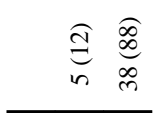 & 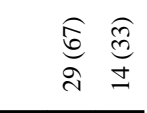 & 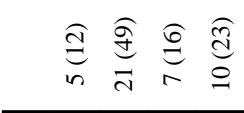 & $\underset{m}{E} \underset{m}{E} \underset{\sim}{E}$ & 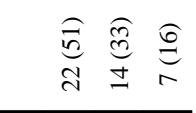 & 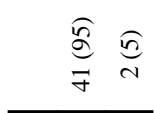 \\
\hline 㝘 & 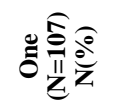 & 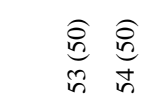 & 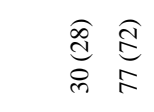 & 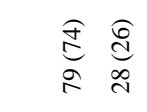 & 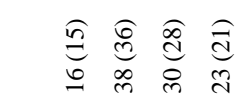 & 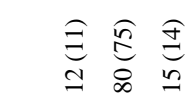 & 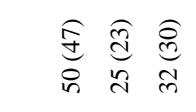 & $\underset{\sigma}{\hat{\sigma}} \frac{\widehat{\infty}}{\sigma}$ \\
\hline 节 & 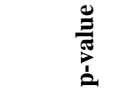 & 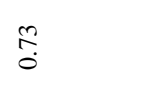 & $\begin{array}{l}\overline{\mathrm{g}} \\
\dot{\mathrm{i}}\end{array}$ & $\stackrel{\infty}{\stackrel{\infty}{0}}$ & $\vec{m}$ & สิ & oे & గి \\
\hline 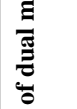 & y & 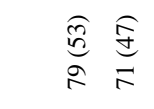 & 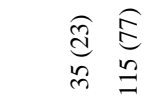 & 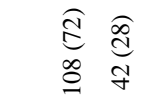 & 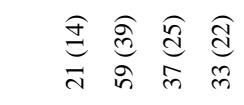 & 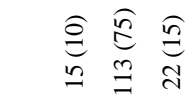 & $\begin{array}{lll}\stackrel{o}{d} & \stackrel{d}{d} & \widehat{d} \\
\stackrel{d}{c} & \text { ले } & \text { ले }\end{array}$ & $\underset{\substack{0 \\
\infty \\
\stackrel{0}{a}}}{E}=$ \\
\hline : & 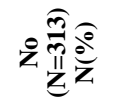 & 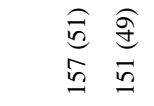 & 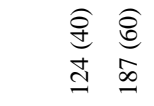 & $\begin{array}{l}\widehat{E} \\
\text { ¿ } \\
\text { ते } \\
\text { a }\end{array}$ & 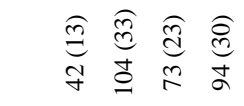 & 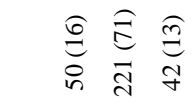 & 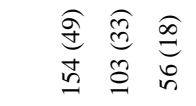 & 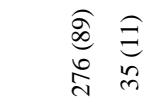 \\
\hline & 产高 & 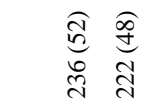 & 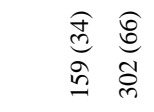 & $\begin{array}{ll}\hat{E} & \widehat{d} \\
\infty & 0 \\
\tilde{d} & \varrho\end{array}$ & 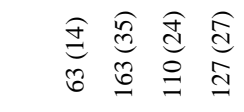 & 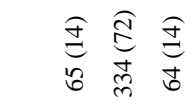 & 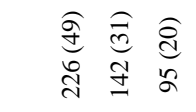 & 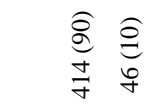 \\
\hline & & 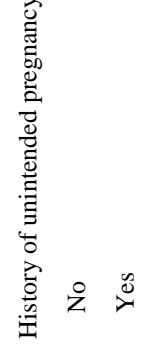 & 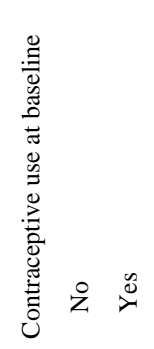 & 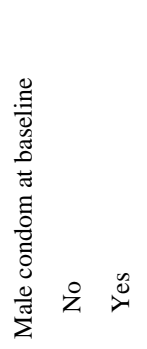 & 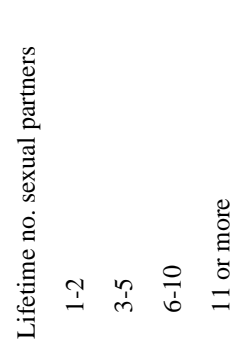 & 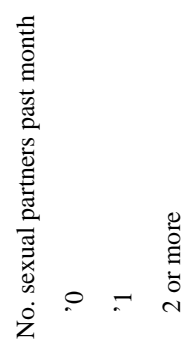 & 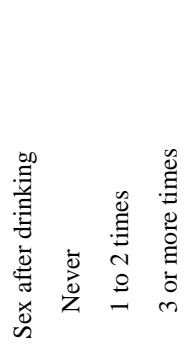 & 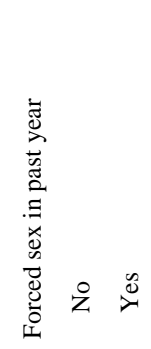 \\
\hline
\end{tabular}




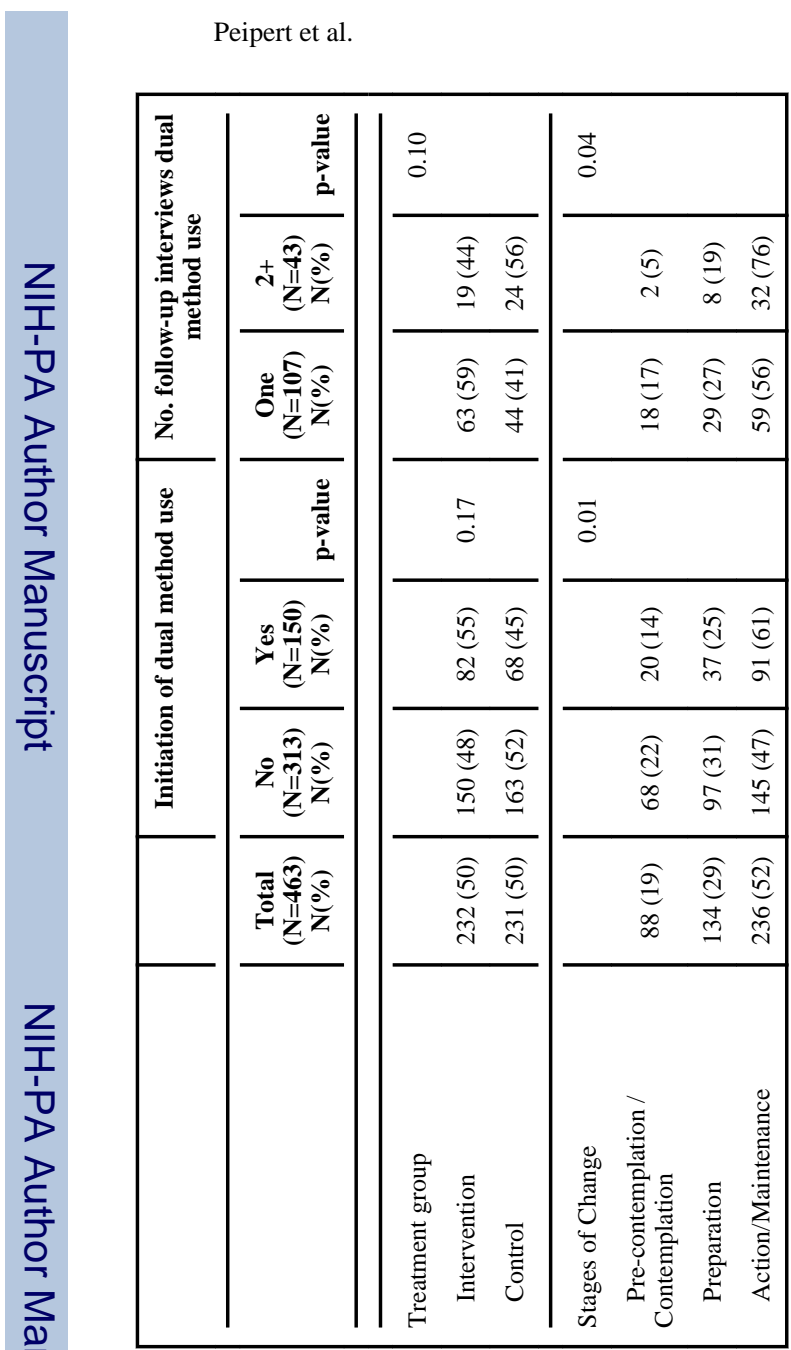

Contraception. Author manuscript; available in PMC 2013 April 10. 
Table 2

Crude and adjusted multinomial regression models for initiated or sustained dual methods use compared to no dual method use (referent)

\begin{tabular}{|c|c|c|c|c|}
\hline & \multicolumn{2}{|c|}{ Crude RF (95\% CI) } & \multicolumn{2}{|c|}{ Adjusted ${ }^{*}$ RR (95\% CI) } \\
\hline & Initiated & Sustained & Initiated & Sustained \\
\hline \multicolumn{5}{|l|}{ Age, years } \\
\hline$<20$ & Ref & Ref & Ref & Ref \\
\hline $20-24$ & $0.97[0.58-1.60]$ & $1.08[0.51-2.29]$ & $0.69[0.39-1.21]$ & $0.61[0.26-1.45]$ \\
\hline $25+$ & $0.95[0.50-1.81]$ & $1.18[0.47-2.96]$ & $0.80[0.39-1.61]$ & $0.77[0.27-2.20]$ \\
\hline \multicolumn{5}{|l|}{ Race/ethnicity } \\
\hline White, non-Hispanic & Ref & Ref & Ref & Ref \\
\hline Black, non-Hispanic & $0.77[0.44-1.33]$ & $0.82[0.38-1.74]$ & $0.81[0.45-1.45]$ & $0.81[0.33-1.95]$ \\
\hline Hispanic & $0.92[0.50-1.69]$ & $0.41[0.14-1.25]$ & $0.98[0.51-1.91]$ & $0.35[0.11-1.14]$ \\
\hline Other & $0.83[0.41-1.69]$ & $0.72[0.25-2.01]$ & $0.98[0.46-2.07]$ & $0.84[0.28-2.51]$ \\
\hline \multicolumn{5}{|l|}{ Education } \\
\hline Less than high school & Ref & Ref & Ref & Ref \\
\hline High school/GED & $1.33[0.72-2.46]$ & $4.68[1.34-6.34]$ & $1.20[0.65-2.24]$ & $4.26[1.15-15.81]$ \\
\hline 2 year degree or more & $2.12[1.17-3.82]$ & $5.81[1.67-0.15]$ & $1.76[0.96-3.23]$ & $4.42[1.19-16.42]$ \\
\hline \multicolumn{5}{|l|}{ Current Smoker } \\
\hline No & Ref & Ref & Ref & Ref \\
\hline Yes & $0.83[0.53-1.29]$ & $0.73[0.38-1.40]$ & $1.11[0.67-1.83]$ & $1.24[0.59-2.61]$ \\
\hline \multicolumn{5}{|l|}{ Substance use } \\
\hline No & Ref & Ref & Ref & Ref \\
\hline Yes & $0.72[0.46-1.13]$ & $0.50[0.26-0.94]$ & $0.66[0.41-1.05]$ & $0.49[0.24-0.97]$ \\
\hline \multicolumn{5}{|l|}{ History of STI } \\
\hline No & Ref & Ref & Ref & Ref \\
\hline Yes & $0.70[0.45-1.10]$ & $0.60[0.31-1.16]$ & $0.76[0.47-1.24]$ & $0.74[0.34-1.60]$ \\
\hline \multicolumn{5}{|l|}{$\begin{array}{l}\text { History of unintended } \\
\text { pregnancy }\end{array}$} \\
\hline No & Ref & Ref & Ref & Ref \\
\hline Yes & $1.06[0.68-1.65]$ & $0.68[0.35-1.30]$ & $1.19[0.75-1.90]$ & $0.62[0.30-1.29]$ \\
\hline \multicolumn{5}{|c|}{ Contraceptive use at baseline } \\
\hline Yes & Ref & Ref & Ref & Ref \\
\hline No & $0.59[0.36-0.95]$ & $0.20[0.08-0.52]$ & $0.63[0.35-1.15]$ & $0.32[0.11-0.92]$ \\
\hline \multicolumn{5}{|l|}{ Male condom at baseline } \\
\hline No & Ref & Ref & Ref & Ref \\
\hline Yes & $0.86[0.52-1.41]$ & $1.17[0.59-2.31]$ & $0.58[0.31-1.10]$ & $0.80[0.38-1.69]$ \\
\hline
\end{tabular}




\begin{tabular}{|c|c|c|c|c|}
\hline & \multicolumn{2}{|c|}{ Crude RF (95\% CI) } & \multicolumn{2}{|c|}{ Adjusted ${ }^{*}$ RR (95\% CI) } \\
\hline & Initiated & Sustained & Initiated & Sustained \\
\hline \multicolumn{5}{|l|}{ partners } \\
\hline $1-2$ & Ref & Ref & Ref & Ref \\
\hline $3-5$ & $0.96[0.48-1.90]$ & $1.70[0.60-4.80]$ & $0.90[0.45-1.78]$ & $1.48[0.50-4.40]$ \\
\hline 6-10 & $1.08[0.53-2.21]$ & $0.81[0.24-2.70]$ & $1.02[0.48-2.19]$ & $0.92[0.26-3.18]$ \\
\hline 11 or more & $0.64[0.31-1.34]$ & $0.89[0.29-2.78]$ & $0.68[0.32-1.43]$ & $0.93[0.28-3.09]$ \\
\hline \multicolumn{5}{|c|}{$\begin{array}{l}\text { No. sexual partners in past } \\
\text { month }\end{array}$} \\
\hline 0 & Ref & Ref & Ref & Ref \\
\hline 1 & $1.51[0.76-2.98]$ & $2.49[0.73-8.45]$ & $1.54[0.75-3.16]$ & $2.23[0.64-7.71]$ \\
\hline 2 or more & $1.49[0.63-3.53]$ & $2.78[0.67-11.4]$ & $1.72[0.68-4.33]$ & $3.57[0.84-15.2]$ \\
\hline \multicolumn{5}{|l|}{ Sex after drinking } \\
\hline Never & Ref & Ref & Ref & Ref \\
\hline 1 to 2 times & $0.75[0.43-1.28]$ & $0.95[0.47-1.95]$ & $0.94[0.54-1.66]$ & $1.35[0.56-3.25]$ \\
\hline 3 or more times & $1.76[1.03-3.02]$ & $0.88[0.35-2.16]$ & $2.25[1.23-4.09]$ & $1.21[0.46-3.19]$ \\
\hline \multicolumn{5}{|c|}{$\begin{array}{l}\text { Forced to have sex in past } \\
\text { year }\end{array}$} \\
\hline No & Ref & Ref & Ref & Ref \\
\hline Yes & $0.73[0.34-1.58]$ & $0.38[0.09-1.66]$ & $0.95[0.41-2.23]$ & $0.63[0.13-3.03]$ \\
\hline \multicolumn{5}{|l|}{ Treatment group } \\
\hline Control & Ref & Ref & Ref & Ref \\
\hline Intervention & $1.56[1.00-2.43]$ & $0.86[0.45-1.63]$ & $1.52[0.96-2.41]$ & $0.89[0.45-1.75]$ \\
\hline \multicolumn{5}{|l|}{ Stages of change } \\
\hline $\begin{array}{l}\text { Pre-contemplation / } \\
\text { contemplation }\end{array}$ & Ref & Ref & Ref & Ref \\
\hline Preparation & $1.13[0.58-2.20]$ & $2.80[0.58-13.6]$ & $1.49[0.72-3.07]$ & $3.87[0.80-18.7]$ \\
\hline Action/maintenance & $1.54[0.84-2.81]$ & $7.50[1.74-32.3]$ & $1.41[0.72-2.77]$ & $5.04[1.09-23.4]$ \\
\hline
\end{tabular}

* Adjusted for treatment group, education, substance use, contraceptive use at baseline, and stages of change 